\title{
ESTETIK CROWN LENGTHENING DENGAN METODE MINIMAL INVASIF：EVALUASI 1 TAHUN
}

\author{
RM. Norman Tri Kusumo Indro*, Leonard C Nelwan ** \\ *Mydents Dental Care, Jakarta \\ ** Indo Dental Center Dental Clinic, Jakarta \\ Korespondensi : RM. Norman Tri Kusumo.I, normankusumo@icloud.com
}

\begin{abstract}
ABSTRAK
Latar belakang: senyum ideal merupakan hasil evaluasi dari analisa wajah dan komposisi gigi. Prinsip desain senyum seperti kategori tipe muka, posisi incisal edge, komponen gigi dan ketinggian gingival merupakan kunci dari harmoni senyum ideal. Metode konvensional crown lengthening dengan pembukaan flap saat koreksi tulang terkadang dapat menimbulkan resiko black triangle. Laporan kasus: pasien datang ke praktik pribadi dengan alasan keluhan estetik. Profil muka didapat long straight, posisi incisal edge saat senyum terlihat lebih dari $3 \mathrm{~mm}$ gingival exposure. Chu's gauge digunakan untuk mengukur proporsi ideal gigi, gingival dan tulang alveolar. Koreksi tulang saat crown lengthening dilakukan tanpa membuka flap (flapless) pada, sehingga mengurangi resiko black triangle. Pembahasan: laporan kasus ini bertujuan untuk mengetahui keberhasilan teknik crown lengthening tanpa pembukaan flap bedasarkan kontrol 1 tahun pasca pembedahan. Prosedur crown lengthening dengan koreksi tulang alveolar dilakukan tanpa membuka flap dan dilakukan kontrol observasi pasien selama 3 bulan dan 1 tahun. Kesimpulan: observasi klinis 1 tahun terlihat stabil. Pengurangan tulang dengan metode flapless pada crown lengthening merupakan alternatif yang menawarkan hasil yang cukup menjanjikan.
\end{abstract}

Kata kunci : black triangle, crown lengthening, estetik, gummy smile

\section{ABSTRACT}

Introduction: the ideal smile is the result of evaluation both facial analysis and tooth composition. The principle of smile design such as face type category, incisal edge position, tooth component and gingival height is the key to ideal smile harmony. The conventional crown lengthening method with open flap method sometimes occurs a black triangle risk. Case report: patients come to private practice for chef esthetic complaints. Face profile was obtained long straight, the incisal edge position when smiling posisition was more than $3 \mathrm{~mm}$ gingival exposure, Chu's gauge was used to measure the ideal proportion of teeth, gingival and alveolar bone. Bone correction following the crown lengthening procedure was done without opening flap (flapless), thereby reducing the risk of black triangle. Discussion: this case report aims to determine the success of the crown lengthening technique without flap opening based on 1-year postoperative control. The crown lengthening procedure with correction of alveolar bone was carried out without opening the flap and control of patient observation was carried out for 3 months and 1 year. Conclusion: one year clinical observation looks stable. flapless crown lengthening method can be an alternative that offers promising results.

Keywords : black triangle, crown lengthening, aesthethic, gummy smile

\section{PENDAHULUAN}

$\mathrm{P}$ rinsip dari desain senyum adalah membangun keseimbangan di antara bibir, gingival dan gigi. ${ }^{1}$ $10 \%$ dari populasi di dunia memiliki gusi yang tumbuh berlebih dan mayoritas pada perempuan. ${ }^{2}$ Jaringan gingival pada bibir atas diklasifikasikan menjadi low, medium dan high. $^{3}$

Prinsip desain senyum seperti mengenal dasar tipe muka, posisi incisal edge, komponen gigi dan tinggi gingival merupakan faktor penting untuk mendapat senyum yang indah. Senyum indah yang diterima secara estetik adalah kategori senyum secara medium dimana semua mahkota gigi incisivus terlihat dan adanya penampakan gingival sekitar 1-2 mm. ${ }^{2}$

Black triangle merupakan kondisi dimana embrasur gingival ke titik kontak interproksimal tidak terisi dengan sempurna. ${ }^{3}$ 


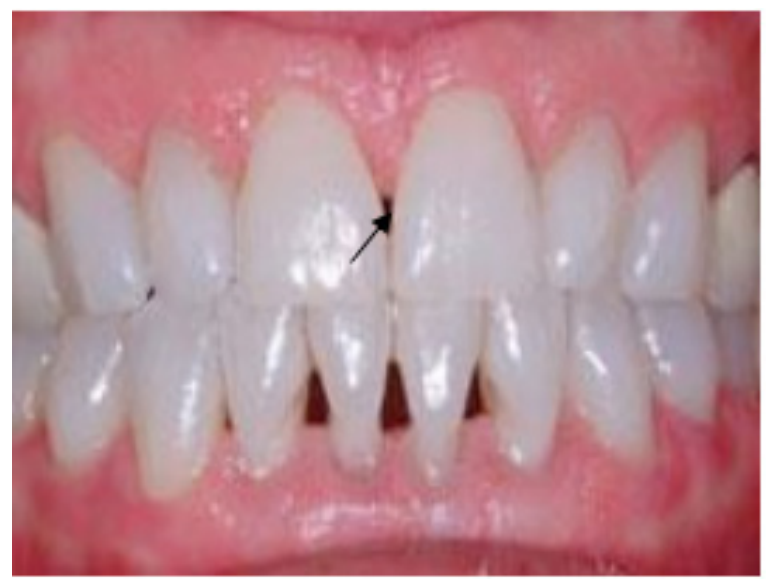

Gambar 1. Black triangle atau open gingival embrasure. $^{3}$

Crown lengthening dengan koreksi tulang memerlukan akses flap,black triangle merupakan komplikasi yang sering terjadi. Berkembangnya zaman menuntut klinisi untuk mengembangkan teknik yang lebih aman dan minimal invasif dari teknik konvensional. Kesuksesan dari teknik ini dipengaruhi oleh diagnosa,penentuan indikasi dan tindakan yang tepat. Salah satu dari indikasi ini adalah pertumbuhan gusi yang berlebihan secara tertunda (altered passive eruption). Pada kasus ini proporsi wajah, bibir dan segala aspek harus dicermati, karena crown lengthening mempunyai teknik yang berbedabeda dan tidak semua harus melibatkan pengurangan tulang. ${ }^{3}$

Observasi hasil crown lengthening merupakan faktor penting karena keberhasilan crown lengthening ditandai dengan tidak adanya keluhan serta tidak terjadi hiperplasia gingiva kembali. Fase regenerasi, jaringan lunak dan jaringan keras akan mencapai fase stabil di bulan ke-3 hingga bulan ke-12. ${ }^{3}$ Kontrol 1 tahun dilakukan untuk mencapai hasil observasi yang maksimum agar tidak terjadi hiperplasi gingiva kembali. ${ }^{4}$

Crown lengthening secara flapless dapat dilakukan dengan bantuan alat khusus seperti mini gingival retractor. ${ }^{5}$ Metode ini mengamankan jaringan periodonsium sekitar dan papilla interdental sehingga mengurangi resiko perdarahan dan secara bersamaan mengurangi tulang dengan memaksimalkan penyembuhan dari jaringan lunak. Flap pun tidak dibuka, jadi mempercepat efisiensi waktu karena tidak perlu penjahitan. Regenerasi penyembuhan pun akan semakin cepat dan nyaman pada pasien. ${ }^{2}$

Teknik flapless ini bukan temuan baru, akan tetapi penulis mengembangkan teknik ini menjadi sebuah standar protokol yang umum agar hasilnya lebih akurat. Klasifikasi dari indikasi ini pun dibuat bedasarkan ketebalan dari gingival pada kasus delayed passived eruption, ketebalan gingival pun harus lebih dari $2 \mathrm{~mm}$ dan pemilihan tindakan crown lengthening setelah melalui pengukuran dari wajah, bibir, gigi, dan gingiva. ${ }^{1,4,6}$

Laporan kasus ini bertujuan untuk memberikan gambaran modifikasi teknik dari pengembangan protokol dari flapless esthetic crown lengthening yang melibatkan pengurangan tulang tanpa membuka flap sehingga memberikan menghasilkan hasil yang cukup menjanjikan dengan resiko minimal. ${ }^{1,5,6}$

\section{LAPORAN KASUS}

Pasien wanita dengan kondisi sistemik yang baik datang ke klinik pribadi dengan keluhan rasa tidak nyaman pada gusi yang terlihat saat senyum. Prognosis pasien baik karena pasien termotivasi tinggi untuk sembuh dan memiliki kebersihan mulut yang baik. Analisis desain senyum menunjukan harmoni bibir yang normal dengan gingival exposure sekitar $3 \mathrm{~mm}$ dari batas bibir atas. Chu's gauge digunakan untuk mengukur ideal proporsi gigi dan gingival serta pengukuran ketinggian tulang (Gambar 2). Setelah dilakukan initial phase berupa scaling dan root planning, diagnosis dari kasus tersebut altered passive eruption yang berhubungan dengan gummy smile. ${ }^{7}$

Pilihan teknik dari kasus ini adalah flapless crown lengthening. Probing awal pun dilakukan untuk menentukan jarak ideal zenith dan marginal gingival saat gingivektomi menggunakan acuan data dari Chu's gauge (Gambar 3).,10 Probing dengan menggunakan probe UNC-15 (Gambar 4). Ukuran ideal Dento Gingival Complex menurut Bhuvaneswaran dkk. (2010) yaitu kurang lebih 3 mm. Jika jarak kurang dari ideal tersebut maka perlu dilakukan pengurangan tulang alveolar. Setelah gingivektomi dilakukan pengurangan tulang secara flapless yaitu dilakukan pelepasan pelekatan sesuai teknik vista tunneling technique, lalu perlahan gingiva dielevasi dengan mini gingival retractor agar tidak tersentuh bur saat pengurangan tulang alveolar. Bur yang dipakai yaitu round diamond bur $10 \mathrm{~mm}$. (Gambar 5). Hasil operasi pada baseline, bulan ke-3 dan 1 tahun dapat dilihat pada gambar 6,7 dan 8 .

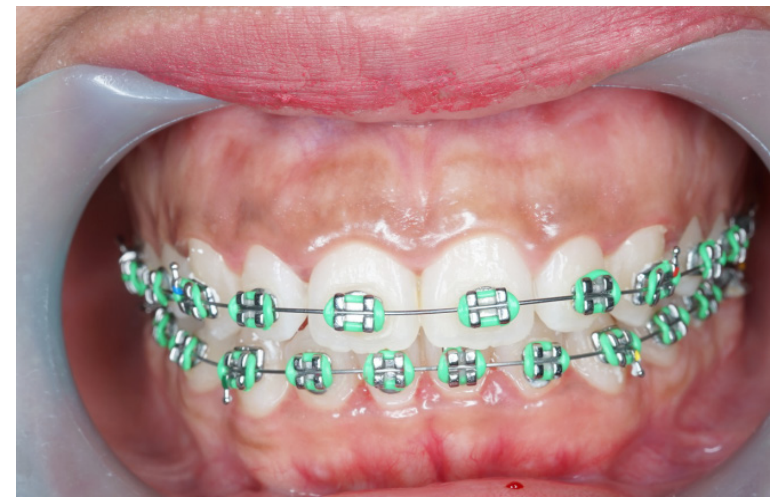

Gambar 2. Diagnosis dari kasus tersebut altered passive eruption 

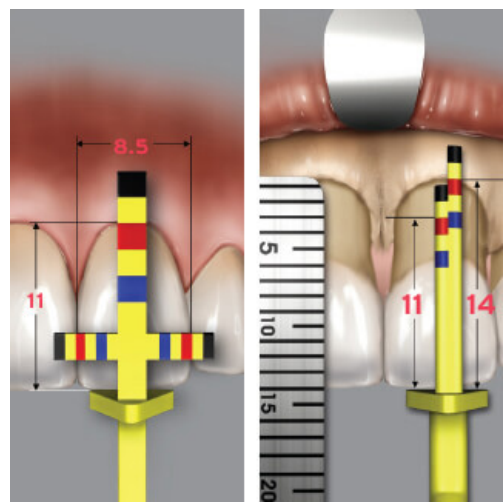

Gambar 3. Chu's aesthetic gauge. ${ }^{10}$

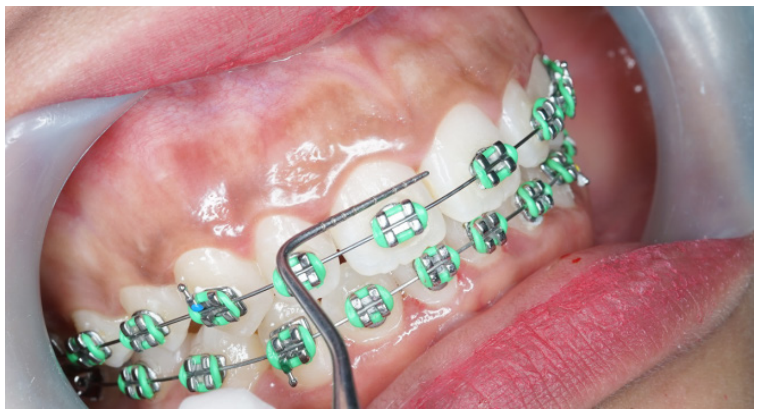

Gambar 4. Pengukuran dengan probe untuk mengukur proporsi ideal dari gigi dan gusi.

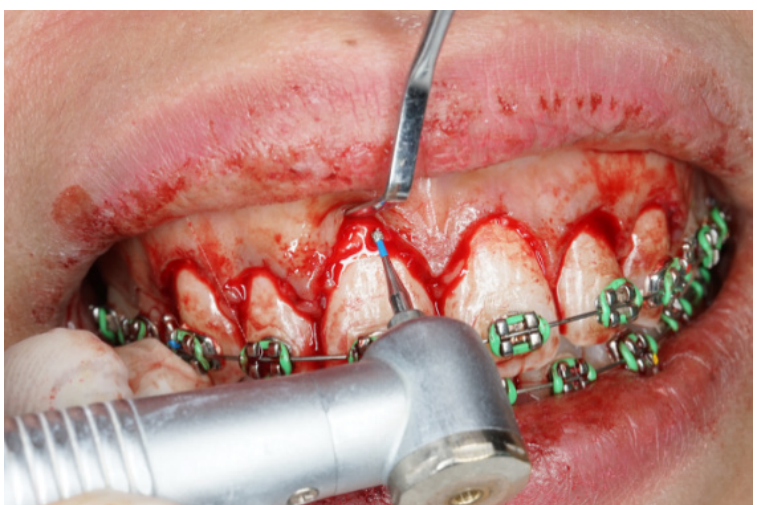

Gambar 5. Pengurangan tulang secara flapless dilakukan dengan round diamond bur $10 \mathrm{~mm}$ dengan perlindungan dari mini gingival retractor.

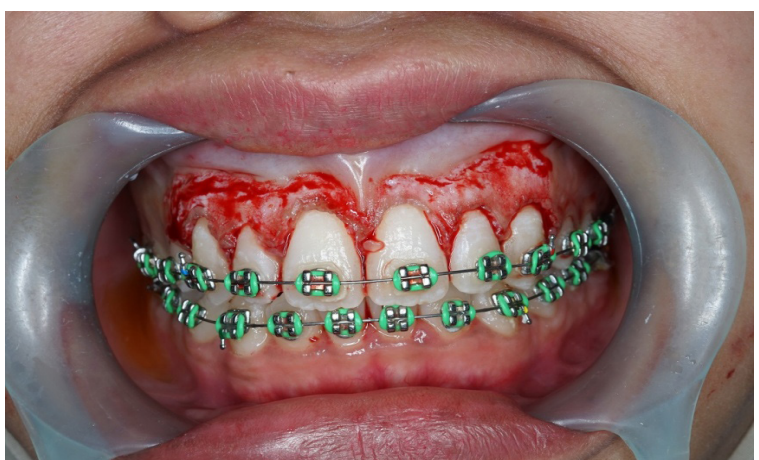

Gambar 6. Hasil Setelah gingivektomi dan gingivoplasti dan pengurangan tulang alveolar

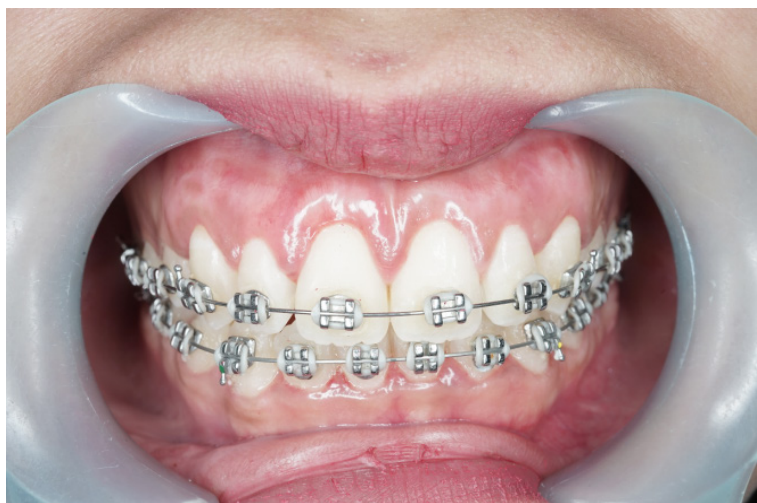

Gambar 7. Kondisi klinis 120 hari setelah operasi

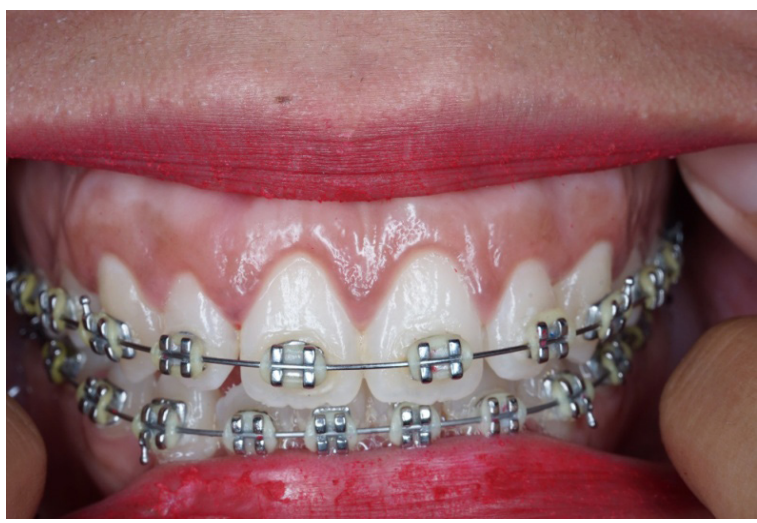

Gambar 8. Kondisi klinis 1 tahun setelah operasi

\section{PEMBAHASAN}

Penambahan prinsip desain senyum pada analisis kasus estetik crown lengthening telah menjadi bagian yang penting karena hal ini pun berhubungan dengan rehabilitasi dengan prostetik. Tujuan dari tindakan pada kasus ini agar terbentuknya marginal gingiva yang berkontur ideal sesuai proporsi sesaat sesudah operasi dilakukan. ${ }^{1}$

Hasil flapless ostektomi dari kasus tersebut dapat berhasil dengan persiapan yang matang dan pendekatan protokol yang benar. Sulkus gingival akan kembali utuh setelah 3 bulan, dan penyembuhan dari jaringan keras nya dari 3-12 bulan tergantung karakteristik dari masing-masing individu 5 .

Kelebihan utama dari teknik ini dibandingkan dengan teknik tradisional adalah mempercepat durasi operasi, mengurangi resiko dari black triangle, dan memaksimalkan penyembuhan primer jaringan lunak. ${ }^{2}$ Tidak adanya visualisasi dari puncak tulang bone crest membutuhkan pengalaman dan keterampilan yang cukup baik dalam operasi. Teknik ini pun memerlukan ketelitian dan penambahan alat yang sesuai indikasi untuk menghindari tersentuhnya gingival saat pengeburan tulang pada ostektomi. ${ }^{2,3,5}$

Laporan kasus Cesar dkk. (2011), menunjukan hasil yang memuaskan pada flapless crown lengthening. ${ }^{2}$ Ribeiro dkk. (2014) menjelaskan bahwa 
hasil perbandingan tanpa dan dengan buka flap crown lengthening pada kasus penelitian observasi selama 1 tahun menunjukan hasil yang sama. ${ }^{5}$ Penulis mengembangkan metode ini dengan teknik bur abrasif agar lebih mudah dikenal dan digunakan secara luas.

Penentuan dari tindakan ini dilakukan selain melewati serangkaian tes yaitu keputusan setelah dilakukan bone sounding dimana pemeriksaan ini merupakan jarak antara cemento enamel junction dan puncak tulang alveolar. Pengurangan tulang alveolar perlu dilakukan jika jarak antara cemento enamel junction dan puncak tulang kurang dari 3 mm. ${ }^{1}$ Tindakan pengurangan tulang alveolar secara tradisional pun memerlukan pembukaan flap untuk melihat tulang secara keseluruhan. Tidak semua crown lengthening memerlukan pengurangan tulang pemeriksaan secara kompherensif pun perlu dilakukan berulang untuk memastikan tidak terjadinya kesalahan human error.

\section{KESIMPULAN}

Hasil crown lengthening akan mempengaruhi hasil perawatan dan kepuasaan pasien. Keberhasilan crown lengthening dipengaruhi oleh prosedur dan tekniknya, ditandai dengan tidak adanya keluhan serta tidak terjadi hiperplasi gingiva kembali. Hasil observasi selama 1 tahun menunjukan hasil yang stabil dari aspek jaringan lunak dan jaringan keras. Flapless crown lengthening dapat dijadikan menjadi salah satu alternatif pilihan dengan konsep terapi invasif yang minimal.

\section{DAFTAR PUSTAKA}

1. Bhuvaneswaran M. Principles of smile design. J Conserv Dent. 2010 Oct-Dec;13(4):225-32. doi: 10.4103/09720707.73387. PubMed PMID: 21217950; PubMed Central PMCID: PMC3010027.

2. Cesar, J.J., Mesquita De Carvalho, P.F, Da Silva C.R., 2011. Flapless aesthetic crown lengthening: A new therapeutic approach, $R$ Mex de Periodontologia. Vol (2) Num.3

3. Al-Zarea et al.; Black triangle Causes and management: A literature review. BJAST, 6(1): 1-7, 2015; Article no.BJAST.2015.061

4. Corrêa BB, Passoni BB, Souza JGO, Pereira Neto ARL, Benfatti CAM. Correcting gingival smile through flapless osteotomy: Predictability with minimal morbidity. Dental Press Implantol. 2014 Apr-June;8(2):64-9.

5. Ribeiro FV.,Hirata DY.,Santos VR., Miranda TS.,Duarte PM., Open flap versus flapless esthetic crown lengthening:12-month clinical outcome randomized controlled clinical trial. J Periodontol. 2014 Apr;85(4):536-44. doi: 10.1902/jop.2013.130145. Еpub 2013 Jul 4.

6. Gupta G.D, Gupta Ramesh, Gupta Nishant, Gupta udit., 2015. Crown Lengthening procedures- A Review article. IOSR-JDMS: 2279-0861. Volume 14 , Issue 4 ver $1 \mathrm{PP}$ 27-37

7. Lavere A.M. Denture tooth selection: An analysis of the natural maxillary central incisor compared to the length and width of the face. Part I.J. Prosthet Dent. $1992 ; 67 ; 661-3$

8. Pound E. Personalized denture procedures. Dentist Manual. Denar Corhup. 1983

9. Bloom DR, Padayachy JN.2006 Increasing occusal vertical dimension- Why, When,How. Br Dent J.200251.6

10. Chu SJ, Tan JH, Stappert CF, Tarnow DP. Gingival Zenith position and levels of the maxillary anterior dentition. J Esthett Restor Dent.2009;21:113-20 